\title{
Existential encounters: Nurses' descriptions of critical incidents in end-of-life cancer care
}

\author{
Maria Browall a, b, * Ingela Henoch ${ }^{\text {c, d }}$, Christina Melin-Johansson ${ }^{\mathrm{e}}$, Susann Strang ${ }^{\mathrm{c}}$, \\ Ella Danielson ${ }^{c, e}$

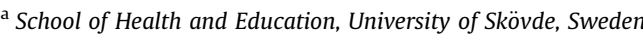 \\ ${ }^{\mathrm{b}}$ Karolinska Institute, Department of Neurobiology, Care Sciences and Society, Division of Nursing, Stockholm, Sweden \\ ' University of Gothenburg, The Sahlgrenska Academy, Institute of Health and Care Sciences, Box 457, SE-405 30 Göteborg, Sweden \\ ${ }^{\mathrm{d}}$ University of Gothenburg Centre for Person-Centred Care (GPCC), Sahlgrenska Academy, University of Gothenburg, Sweden \\ e Mid Sweden University, Department of Nursing, 83125 Östersund, Sweden
}

Keywords:

Cancer

Existential encounters

Critical incidents

End of life care

Nurses' experiences

\begin{abstract}
A B S T R A C T
Nurses working with cancer patients in end of life care need to be prepared to encounter patients' psychosocial and spiritual distress.

Aim: The aim of this study was to describe nurses' experiences of existential situations when caring for patients severely affected by cancer.

Methods and sample: Nurses (registered and enrolled) from three urban in-patient hospices, an oncology clinic and a surgery clinic and a palliative homecare team were, prior to the start of a training program, invited to write down their experiences of a critical incident (CI), in which existential issues were featured.

Results: Eighty-eight CIs were written by 83 nurses. The CIs were analyzed with qualitative content analysis. Two main themes were found: Encounters with existential pain experiences, which concerned facing death and facing losses; and Encountering experiences of hope, which concerned balancing honesty, and desire to live.

Conclusions: This study points out that health care professionals need to be aware of patients' feelings of abandonment in exposed situations such as patients' feelings of existential loneliness. That there are some patients that express a desire to die and this makes the nurses feel uncomfortable and difficult to confront these occurrences and its therefore important to listen to patients' stories, regardless of care organization, in order to gain access to patients' inner existential needs.
\end{abstract}

(c) 2014 Elsevier Ltd. All rights reserved.

\section{Introduction}

Nurses working with patients severely affected by cancer at the end of life need to be prepared to encounter patients' psychosocial and spiritual distress. In a survey by Chochinov et al. (2009), patients receiving palliative care experienced various kinds of distress at the end of life. They reported having problems facing the physical, psychological, existential, and spiritual challenges associated with their experiences. Existential distress was reported to be experienced most by those who were inpatients, had been educated, and who had a partner. Results for the use of spirituality, particularly its existential aspect or "sense of meaning and purpose", were associated with less levels of distress for those patients.

\footnotetext{
* Corresponding author. Department of Neurobiology, Care Science and Society, Division of Nursing 23300, 14183 Huddinge, Sweden. Tel.: +46 56854283873.

E-mail addresses: maria.brovall@ki.se, maria.brovall@his.se (M. Browall).
}

There are no exact definitions with regard to spiritual needs, as different people emphasize different facets or interpretations of this construct. In health care contexts, spiritual care normally includes religion and general spirituality, but less often existential issues as defined within existentialism. It is impossible to draw a dividing line between these concepts. "Spirituality" generally comprises the following domains: meaning, transcendence, energy, and relationships. In religion there is a God and individuals who share the same beliefs, worshipful acts within some kind of social institution. Existentialism comprises the questions of life, the basic condition of being human, where freedom, existential isolation, meaning and death become central issues (Strang, 2006; Aldridge, 2000; Yalom, 1980)

Patients expect healthcare staff to be comfortable discussing existential issues with them and that staff address these concerns sensitively (Yardley et al., 2009). In interviews with patients 
receiving palliative care and palliative healthcare staff about the optimal content of end-of-life discussions, existential issues were found to be important to both groups, although healthcare staff did not feel that it was their role to discuss such issues. (Clayton et al., 2005). According to Chochinov et al. (2005), healthcare staff should better understand the importance of existential issues and their impact on the will to live of patients who are near death.

Although patients need existential support, it has been stated that healthcare staff sometimes fail to support the patients in regards to these issues (de Vogel-Voogt et al., 2007; Strang and Strang, 2001), that training healthcare staff in existential issues is insufficient and that there is a vagueness concerning their role in these situations. (McSherry and Cash, 2004; Strang et al., 2002). In a review of the literature concerning the ability of staff to alleviate existential distress, it was found that although clinicians are sometimes aware of their lack of knowing what to say and or do when patients experience existential distress, they are often aware of existential distress or spiritual meaning as being part of their work (Leung and Esplen, 2010). In order to meet patients' needs to express existential concerns, nurses have been found to develop relationships of trust through effective communication skills (Mok and Chiu, 2004; Johnston and Smith, 2006). Alternatively, assistant nurses find it unnatural to talk about death with patients or their relatives and report that caring for dying patients provokes negative emotions (Beck et al., 2011). A study among healthcare staff at nursing homes found that they expressed a fear of death. They attempted to keep death at a distance by concentrating on practical tasks and avoiding elderly patients who were dying and not becoming involved on a deeper level in the life situations of the elderly (Österlind et al., 2011). In a focus group study, healthcare professionals' opinions about important existential issues among patients with cancer were explored (Browall et al., 2010). The study showed that the healthcare professionals were aware to some extent of important existential issues among cancer patients and how to address those issues, but it also revealed that they often fail to take the initiative to discuss them.

Bodily symptoms are common in progressive cancer and mean that patients are living in a distressed and weakened body, which often is perceived as a threat to the person as a whole. This situation may have severe consequences and lead to a desire for death or a hastened death, and the situation can control the person's whole existence (Rasmussen et al., 2010). Earlier studies that examined the commonness of symptom distress among persons near death usually focus on the physical challenges and, to a lesser degree, psychological challenges. Symptom distress is complex and it is crucial that healthcare staff, when encountering dying patients, understands and recognize the most vulnerable persons (Chochinov et al., 2009). Many patients with cancer have a desire to share their existential concerns with healthcare professionals (Yardley et al., 2009), and professionals are aware of this need (Browall et al., 2010) but the question is whether they are able to identify specific opportunities to participate in conversations about patients' existential needs.

The aim of this study was to describe nurses' experiences of existential situations when caring for patients in end-of-life cancer care.

Additional questions was: "What happened?"; "What were your thoughts about this?"; "What were your emotions?"

\section{Methods}

This is a qualitative study where the Critical Incidents Technique (CIT) was adopted (Flanagan, 1954; Bradbury-Jones and Tranter, 2008). The study was conducted in Sweden during 2010-2012, and is part of a larger study involving a randomized, controlled trial with a training intervention that focuses on existential issues and nurses' attitudes to caring for dying patients. Nurses (registered nurses and enrolled nurses) invited to participate in training about existential issues (Udo et al., 2013; Henoch et al., 2013) were asked to write down their experiences of a critical incident $(\mathrm{CI})$, prior to the start of the training intervention, in which existential issues were featured. This was to ensure that the educational material or the fact that the intervention was built on reflections did not affect them. Of the 102 participants in the training intervention, 83 nurses wrote about 88 CIs.

\section{Sample}

Registered nurses (RN) and enrolled nurses (EN) from three urban in-patient hospices, an oncology clinic and a surgery clinic were invited to participate. There were 42 from hospice care $(\mathrm{H}), 22$ were from the oncology clinic in a rural area (OC), 12 were from a surgical clinic (SC), and seven from a palliative homecare team (PHT). Sixty-two percent were RNs and 38 percent ENs. All participants were women and the mean age was 45.6 years (SD 11.6), median 48 (range 24-64). They had worked an average of 1.8 years (SD 12.0) in palliative care, median 16 (range $1-46$ ).

\section{Data collection}

All of the participants were asked to write down an example of a $\mathrm{CI}$ in their experiences where existential issues in end-of-life care arose. The concept of the 'existential' was not described to the participants prior to data collection; they could interpret the term without guidance from the research team. Additional questions to support the narratives of the CI were: "What happened?"; "What were your thoughts about this?"; "What were your emotions?" Bradbury-Jones and Tranter (2008) have indicated that the presuppositions of Critical Incidence Technique (CIT) have sometimes been challenged, but we included any description that included a situation with existential issues, regardless of clear demarcation of beginning and end or how detailed it was. Some descriptions were very detailed and some briefer.

\section{Data analysis}

The specific CIs were the basic unit of analysis and were analyzed with qualitative content analysis (Krippendorff, 2004). The analysis was performed step-by-step in order to describe prominent themes, categories and sub-categories. The transcripts were read through several times by the first author (MB) to obtain a sense of the totality. One other author $(\mathrm{IH})$ read a sample to obtain a sense of the content in this particular sample. Units of meaning addressing different aspects of CIs were identified and extracted, and were subsequently condensed and labelled with a code that adhered closely to participants' descriptions. All codes were checked back with the units of meaning and the interview text and some codes were changed. This analysis was repeated several times. All codes were compared based on variations and similarities and were used to form tentative sub-categories and categories that were discussed and revised several times by the authors before they were finally arranged into two main themes of four categories and six sub-categories. This is an example of an inductive analysis in which patterns and themes of analysis "emerge out of the data rather than being imposed on them prior to data collection and analysis.'(Patton år, p453). All authors are registered nurses and researchers with experience of caring for patients in different phases of cancer and participated in the process of reflection and discussion about the agreement of sub-categories, categories and themes (Krippendorff, 2004). 


\section{Ethical considerations}

The study was approved by the Regional Ethics Committee in Gothenburg (Dnr 426-08). The participants were given verbal and written information about the study and gave informed consent to participate. All participants was given a telephone number to the responsible researcher and was also encourage to take contact if any emotional questions or thoughts was raised after participating in this part of the interventions. Also, the course leader of the intervention study encourages the participants to talk and share if there were any thoughts or worries after writing the $\mathrm{CI}$ narratives.

\section{Results}

The analysis of the nurses' experiences of existential situations when caring for patients in end-of-life cancer care, as expressed in the $\mathrm{CI}$ narratives, formed a structure comprising two main themes; Encounters with existential pain experiences and Encountering experiences of hope. Four categories, and six sub-categories were also formed (Table 1). Themes, categories and sub-categories are presented below, and are illustrated with quotations from the CIs, labelled by care organization (H, OC, SC or PHT) and number of participants (Table 2).

\section{Encounters with existential pain experiences}

\section{Facing death}

Anxiety and insecurity. Nurses' encounters with existential pain experienced by patients severely affected by cancer concerned the patients' anxiety and insecurity about death along with strong feelings about their dying combined with feelings of anxiety and panic. Patients expressed fear that it would hurt to die, and that no one would understand their needs at the end of life. The difficulty of waiting for death and the grief that patients felt about their own death was often expressed as pain and anxiety, and their questions to the nurses were about the actual moment of death, such as what they can expect to feel, and what will happen, physically, with their bodies. (OC7). Nurses particularly described the difficulties of encountering the experiences of younger patients and agonizing about how unfair they, and the young patients, regard the whole situation.

Nurses' feelings of powerlessness in facing death and dying touched them deeply as well as feelings of insufficiency and uncertainty about how to respond and relate to these situations. They could not stop thinking about certain events and remember these particular occasions and patients with great sorrow, a long time after they died. They felt relieved when they themselves, in painful situations, could show openness, a skill, which facilitated the patients and families themselves to open up about feelings and questions about dying and death. They sometimes became hesitant about how open they should be, but usually the patients themselves would ask for clear and straight answers, giving permission for the openness to begin.

Feelings about the importance of having the courage to be emotionally intimate and take the time to sit down and let the patients tell their story and try to inspire hope were described.
Some of the nurses described that they felt special; to be chosen by the patient as the one they felt able to communicate with about their most difficult issues concerning death and dying. Some described feeling privileged to be let in and be involved in the patient's life in this way and to have access to so many life stories.

Encountering the patient's desire for death concerned the hardships of listening to stories about their desire for death. In these situations the worry and anxiety were so severe that the patient could not see any other way out but death. The nurses also described that patients often became depressed and sad and felt that no one cared about them and that they might as well die. Some patients expressed a desire to die, and in extreme cases took their own lives because they did not have the stamina to wait for the end. Such situations were perceived as being extremely difficult for the nurses. On many occasions, patients said that they only wanted to continue to live for their family's sake and if it had not been for their families they would have made an end to their suffering. When the patient expressed a desire to die, but relatives were opposed, this situation was perceived by nurses as being ethically and morally difficult. They also described that they felt trapped when providing care to patients who expressed a desire to escape that lifesustaining care (H2).

\section{Thoughts and dilemmas}

The nurses acknowledged the difficulties of meeting patients' sadness over the injustices about not being healthy and being close to death. Existential episodes of this kind were perceived as being difficult to meet, and created anxious thoughts in the nurses (OC2). In these situations some patients were challenging and demanding and, despite this behavior, nurses felt empathy towards them and felt that it was important to devote time to these patients as they were in the most need of special support. Nurses thought it was important to gain an understanding of how they themselves would react in these situations and how to support patients' independence. Positive situations were also described, such as when patients expressed their thoughts and feelings about death and nurses had persevered and listened without changing the subject (H8).

The nurses also described existential dilemmas when caring for a person over a long period of time without being aware of the person's wishes: how they wanted their last moments to be spent and their body to be cared for after they had died. If the family members seemed happy about these arrangements, nurses thought that they had succeeded in their responsibility and felt satisfied. Situations when they had not met the person's needs in the first place were also mentioned, for example, when they had mobilized the patients without first taking into consideration the person's own will.

\section{Feelings of guilt and punishment}

Many of the nurses expressed that patients often had existential questions about guilt and punishment; for example, they reminded themselves of what they had done earlier in life and believed that what happened now with the disease may be a punishment for these actions (H31). Even relatives of patients could sometimes insinuate that the illness could have come about as a result of guilt

Table 1

The categories, sub-categories and themes.

\begin{tabular}{|c|c|c|c|}
\hline Themes & Encounters with existential pain experiences & & Encountering experiences of hope, \\
\hline Categories & Facing death & Facing losses & Balancing honesty \\
\hline \multirow[t]{3}{*}{ Sub-categories } & Anxiety and insecurity & Identity and normality & \\
\hline & Thought and dilemmas & Loss of control & \\
\hline & Feelings of guilt and punishment & Relationship & \\
\hline
\end{tabular}


Table 2

The different quotations to clarify the two main themes, six categories and five subcategories.

\begin{tabular}{l}
\hline Categories and subcategories \\
Facing death \\
Anxiety and insecurity
\end{tabular}
Themes

Encounters with existential pain experiences

"The patients was dying of cancer, his wife said he had some concerns. I looked at the patient, who looks away, looks uncertain. I stay quiet there and then he says, 'How do you know when it's time?' I answer, 'You think about death?' He nods. 'You mean physical signs?, I continue. 'Exactly', he says. His wife seems surprised by his answer. At first I was surprised that the issue was raised at that time, I was not sure how 'straight on' I'd be in my answer to his question, because I felt that he and his wife were at different levels. On the other hand, I was relieved that he asked the question, and thus opened a conversation about death" (OC7).

"A young woman with a severe muscle disease was completely paralyzed, could not speak, but communicated through eye blinking. A relapse led to hospitalization. A year earlier, she had established a contract with her doctor, in which she declines all life-sustaining treatment. The mother did not accept her daughter's illness, implored and demanded that everything was done that could be done. What could be done was a pretty extensive surgery, and gavage was started. At each time the gavage was started, the eyes of the woman that said she did not want to, but we continued. It was offensive that we did not take her wishes seriously. The mother came several times a day with great despair, anxiety and hope of recovery. The operation was performed. We felt that it was a severe conflict between the daughter's wish and the mother's hope. The important thing was the mother's willingness to do the utmost for her daughter. The girl died after a month. The time allowed the mother to accept and cope with the disease, because everything that could be done had been done. We felt that daughter suffered for the mother's sake. So she could move on in life."(H2)

Thoughts and dilemmas Tried to keep in mind that she was in need of help and did not mean to be difficult. Difficult to answer her questions, why do I feel so bad? Will I die today? Hard not to feel sorry for her but sometimes hard to get the patience to suffice. Many perceived that as nagging but I thought it was the most sad, as she was so anxious. (OC2)

"I worked in home health care during a weekend and had many patients to care for. I came to a very sick woman who I had never met before. I should have dressed a wound on her ear, but there was not enough dressing material. Then she said, "Sit down for a while." Then she asked about death and we talked for a while about it. She was very grateful and said that what I said was consistent with what she was thinking. She thought it was liberating to express her feelings and that I did not avoid the subject. The ear was not dressed. For me, there was no doubt that I would sit down. I think I could answer the questions honestly. There was nothing uncomfortable about it. I felt happy throughout the day. The fact that I took the time. What is an ear in comparison with major life issues? I did not have a bad conscience for not dressing the ear. The essential thing is that I took the time, was present, and met her where she was." (H8).

\section{Feelings of guilt and punishment}

\section{Facing losses}

Identity and normality

Loss of control

Relationship

Balancing honesty

Desire to live
"I had just done something "practical" in the room. It was relatively quiet in the department and I did not feel stressed. Therefore I stayed in the room for a bit, and showed that I was not in a hurry. It was almost like I had a hunch that she wanted to talk. I sat next to her and she asked if I wanted to stay with her. I asked if she wanted to "talk" about something. Immediately came a story of guilt. Something she had done earlier in life tormented her now. She said she was afraid of God's punishment for her "indiscretion", error and sin." (H31)

"Patient with sarcoma of the jaw that has undergone major surgery of the facial region. This has led to major changes in the patient's appearance and also changed the power of speech. The patient had a psychologist contact both before and after surgery, and had many questions for us on the staff. Coming in to the patient one evening when she cries. I ask what's the matter?She is saddened by how she looks and how she talks. She asks me if she will ever be able to recognize herself, feeling like her usual self, having her normal function and be able to cope and live as she did before the disease. She asks me if she ever is going to be able to live a normal life after all she has gone through"(OC20)

"I think of a 40-year-old man, a captain, who was diagnosed in another country where he was with his ship. He came to our department and seemed totally manic and out of touch with reality. He was the captain and was used to "controlling" his environment. Now he was suddenly terminally ill and could not control what happened. When I think of him I think of a captain facing a storm without warning and completely unlike what he previously had. He lacked the tools to deal with it. There was chaos for him and his family. This result is that he attempted to steer an entire surgical department staff, large and small." (PHT 1)

"I'll tell you about a severely ill woman with cancer. She came to our department after her GP thought that she had become worse. She had been diagnosed with liver cancer. She was surprisingly alert and talkative. She had a really nice family, understanding husband, two teenage girls and a spirited alert mother, they were a nuclear family. She was still working part-time at her job, which she had before she become ill. We were the same age; it differed 2 years between us. We found each other because we had a common interest in dogs; she had a Labrador that she loved above all. Every time I was working, I was in to see her and we talked for a while about dogs of course, but also other things about her situation, that her life and the days were numbered. She asked often and wondered how much time she had left, what do you answer to that? I do not know, you could say, just be there and listen. Her family was her great support, they were absolutely fantastic. They did not leave her alone, they were by her side the entire time. Whenever you went in to her, she could make jokes, laugh and cry, though the situation was as it was, so you were always glad to talk to her. She could see a "light after this". Then comes the day when it happens. You become sad, but you're supposed to be professional, have a professional role and give professional support, console, be available for family members. What do you think at these times? You think it's unfair, hopeless and you can't understand why some people get such a short life and others not."(PHT17).

"A young woman came to us with suspected malignancy. After examination and testing it was revealed that there was a large tumour, which had grown over many other important organs. It was not a good prognosis for survival. The woman in question was so young that she thought that she had not had time to LIVE. No family of her own with husband and children. Afraid to die. Did not want to die. We who nursed her felt powerless. Could not help her in any good way. How could we comfort her, when we could go home to our homes in the afternoons, home to our children? A large part of her bitterness was that she would not have time to have a baby and she was a little aggressive towards us as we were healthy." (PHT19)

Encountering experiences of hope

"One day the woman's son called and asked how seriously ill his mother really was. He noticed that Mom was getting worse and wondered why we did not do anything. I asked him what information he had received, and told him that I would come back later when I had talked with the patient. I suspected that the patient had not told her children what the situation was. The woman herself was well informed by the doctor and I felt that she and her husband were both involved in the entire process. I asked her if she had told her son about his illness. She said that the children (she had two sons) knew that she had been treated for cancer but she had chosen to leave them out when it came to the information that the disease no longer was possible to cure. The patient stated that she chose not to tell their children, to protect them. She also stated that she could not be bothered to deal with this now, despite her son's concerns. I asked the patient if it was ok for her if a doctor or nurse informed her son instead." (SC1)

"Hard to find a balance between letting the patient have hope and being realistic and honest. Have a feeling of being insufficient for the patient. Localization of the department also so that I have a hard time picking up the threads patient leaves, then I know other patients listen. My fear is that he will die, without knowing that he was dying." (OC26)

"On this occasion, we had a 95-year-old woman with us. Despite her illness, she was happy; yes you felt happiness entering her room. I brought a visiting baby boy into her room and sat on the edge of the bed. She was surprised by the visit and we started talking about life, 
Table 2 (continued)

about meaning ... about the beginning of life and end of life. That his [life] had just started and that her life was coming to an end. She regretted nothing, except that she probably thought she was too busy when the kids were small. She wishes she had taken more advantage of that time. Then she said: "Do not buy so much stuff that just is in the cupboard; spend the money on experiencing things, because it is these memories that make me feel good today. I wish I had done it more." This conversation was so good, I could really feel how strange life is with the little baby in my lap, and the old woman next to me. Extremities of life in some way." (H6)

"I felt that the patient wanted to talk and asked if he wanted to have a professional contact. He then stated that he did not want to sit with a psychologist and dwell on how it is going to be when he was dying. When the workload on the ward was quite slow, I said we could sit and talk about life instead. He told me about his life, his experiences and how he looked at life. A colleague said later that he talked a lot about how he appreciated our conversation - that we are not focused on death but on life. Later in the patient's treatment when it began to be signs of treatment failure I had a conversation with the patient when it became evident for him that he would not live much more - that he had to feel whether he could take more treatment or not. When he was about to leave and go home that time, we both knew that we would probably not see each other again. I felt that he appreciated our friendship and that our conversations had significance for how he dried struggle through the treatments. I felt that he had a need to share the joy of life he had and that he understood that I was inspired by it." (OC9)

"At $2 \frac{1 / 2}{2}$ years control came a girl, pale with bad blood values, leukemia. She had undergone bone marrow transplantation, she was isolated a month with her mother. Lived until she was 9 years old. Shortly before her death, I was at a home visit, I asked what she was doing. She planted seeds so there would be something living after her when she was dead." (H30)

for past sins, a situation towards which nurses felt was very difficult to relate. Patients wished to die from their suffering, but when they did not, they therefore believed that it was God's way of punishing them. The nurses felt that in these situations the patients wanted acknowledgment, empathy and comfort. Patients wanted to hear that they had done nothing wrong and had no debt to pay. Because these situations were difficult to manage, nurses often felt humble and insecure when these feelings were aroused.

\section{Facing losses}

\section{Identity and normality}

The nurses described it as difficult when patients were struggling to avoid losing their sense of identity and normality and being treated the same as they were before they became ill. The patients' grief often encompasses the loss of their 'normal appearance'; the sense of what is 'me'. It was very difficult for the nurses to encounter patients' feelings of being different and the frustration they felt over this loss (OC 20). It appeared that some patients did not want to tell close friends or acquaintances that they were sick, because they did not want to be pitied or to feel discriminated against; they wanted to have the free choice to choose whom they told or what to tell. Furthermore, they wanted to engage with everything that was difficult, for example, in their legal will and testament, and to solve practical things as quickly as possible so that they could put these behind them and not think about them any longer.

\section{Loss of control}

To be well informed about test results and the course of the disease became very important to patients in order to feel that they still had control over their lives. Different dilemmas arose for some patients who received information that they did not have much time left to live and how difficult it was for most people to understand this fact, particularly when they felt well and perceived that they still had a degree of time. The nurses described that some patients experienced a loss of control because they had been accustomed to having control and self-determination and now that they were seriously ill they had lost this ability. To compensate for this loss, some patients tried to dominate the nurses and made unreasonable demands on them to somehow maintain their feelings of control. Nurses expressed that those patients they perceived as demanding had a lot of anxiety and often rang the bell, making some nurses irritable and unwilling to approach the patient. This created tensions within the team as some said they understood and were willing to respond to these people while others had no understanding of these feelings and were reluctant to yield to these demands (PHT1).

It was also important to the nurses, however, to respect the patients' needs to contemplate and allow them space alone with their thoughts. But some of the nurses expressed strongly that existential dialogues were seen as difficult and they often felt sad and inadequate after the conversation with the patients. Thoughts like, "Have I really been able to help and contribute something?" were often expressed afterwards.

\section{Relationship}

The nurses described how patients missed their relatives, who, due to advanced age, could not come to visit. These patients became very lonely and isolated when they became seriously ill. Other patients could not bear to meet their families and chose instead to withdraw, while others grieved because they could not meet with their relatives. For patients with small children, it was common for them to feel guilty when they could not manage to spend as much time with their children as they would like. These feelings caught up with the patients when their remaining time in life was limited. Nurses who had children of the same age as the patients' children thought it was difficult to keep a professional distance. Their identification with other parents brought forth their own anxieties and fears about not being available for their own children. Some of these encounters could be very rewarding, however, and they sometimes felt almost like they were losing a friend (PHT17). They felt very sad about patients who were young and who had not had time to have children and the fact that they would not have time to experience becoming a parent (PHT19). Patients shared their thoughts and worries about being left alone, or being abandoned during the last stage of their lives when relatives and friends were reluctant to come and visit because they themselves were afraid of incurable diseases and death. Patients were also afraid of being forgotten after they had died. Patients who were deprived of the opportunity to be with their families because of illness, for example, patients who had been on leave from hospital with their children and had come back, were very sad and cried a lot as they realized that they could not take part in life in the same way as they did before. The nurses were privy to countless family dramas, where patients were worried about how the family would cope when they did not remain as mediator to resolve conflicts and problems, or how it would be for the partner who was left alone. Many patients thought a lot about how to plan their lives and the time they had left to do everything they wanted. These 
thoughts occupied much of their time and took hold of them with great force.

\section{Encountering experiences of hope}

\section{Balancing honesty}

Some nurses described the experience of powerlessness when they as healthcare staff needed to withhold information about investigations and results of tests. Being forced to say to a patient that you know nothing, before the doctor had provided information to patients and families, was perceived as being a particularly difficult dilemma. It was a dilemma when the nurse understood that patients did not tell their families and especially their children about the seriousness of the disease or diagnosis (SC1). They felt a sense of powerlessness and fear when having to deprive the patient of hope but they believed that it was important that the patients took advantage of the time together with the family and not focus their energy on the wrong issues. They expressed that they often ended up in an ethical dilemma when they wanted to respect the patient's desire to protect their children while at the same time it was important that the families were well informed so that they in turn were able to do and say what they wanted.

The nurses described the difficulty that many of the patients experienced as they hovered between having an insight into their situation only to then suddenly deny it. The patients perceived themselves to be stubborn and strong, having the power and will to try to live the best they could, even though they knew that time was short. They expressed a fear and dilemma of not being able to be honest with the patients, and how they were afraid to take away patients' hope or to inspire too much hope when this was not realistic (OC26).

\section{Desire to live}

The nurses described the patients' desires to focus on life, to be strong, both for their own sake and for the sake of their families. The patients wanted to live life to the full for as long as possible and for as long as they could. There were also descriptions of conversations about the meaning of life, where patients looked back at their lives. They spoke of how one weighs what you have done and have not done, and shares what you see now in retrospect that you would have done differently. This type of reflection often took the form of giving good advice to the nurses (H6).

Encounters such as these awoke feelings of insecurity in nurses; for example, did the patients want to talk about the possible prognosis and conditions of the disease, or did they just want to focus on what was the healthy course of action for them? The nurses hesitated and often did not know how to respond to these incidents to support the patient properly (OC9). In the conversations where the focus was on life and the powerlessness that the patient felt, nurses experienced a strong sense of an affinity and that they had the power to help even more through this affinity. They described a certain friendship that occurred within these meetings and that these discussions provided insight and power in both directions, reciprocal to both the patient and nurses. The nurses described patients' will to live and fight in spite of heavy losses. Patients would encourage conversations with the nurses about their lives and how important it seemed to share their life experiences. Many patients simply tried to maintain a perfect image and always tried to be positive and happy. The nurses experienced that those families who were on hand and stood up for the patients facilitated the effective care of these severely ill people.

The nurses felt comfort in the knowledge that they formed a closed circuit of support around the patient. Some patients never gave up the idea that they would survive; they convinced themselves that they would survive and not die (H30). The nurses felt that in these situations of hope that it was extremely important to listen and not try to say as much. However, they often described their experiences of working so intimately with grief and death as being trying and wearisome, when they knew the patients' more distressing situations were so close.

\section{Discussion}

When encountering dying patients, nurses in the present study working in different care organizations shifted between feelings of powerlessness, insufficiency and uncertainty about facing death and dying to a feeling of relief for the openness in the close relationship that they developed with both the patients nearing death and their relatives. Being involved in close relationships may be challenging as well as mutually beneficial, and requires that nurses are present, listen actively, and are compassionate (Iranmanesh et al., 2009). Nurses in our study described that it was a privilege to be let in and involved in the patient's life, and, as Iranmanesh et al. (2009) describe, it also provided a new insight into the nurses' own lives. It was also a privilege to have access to so many life stories, which, according to Taylor (1997), provides entrées into patients' life histories. Previous critical life events, relationships, the meaning and uncertainty of everyday situations and lived experiences may be exposed in these exchanges. Stories also provide nurses with information for assessment purposes (Pelusi and Krebs, 2005; Taylor, 1997). In our study the nurses described the importance of being emotionally close and having the courage to open up to allow communication about death with patients and families. Having openness and encouraging patients' storytelling is of much importance as it is therapeutic, promotes coping strategies and connectedness as described in earlier studies (Pelusi and Krebs, 2005; Taylor, 1997) According to Missel and Birkelund (2011), existential phenomena may be exposed, which are, as Taylor (1997) describes, components of significance for spiritual health.

Encounters with existential pain experiences with dying patients in this study meant taking part in patients' existential anxiety, insecurity and fear. This was also found in a study by Adelbratt and Strang (2000) and Strang et al. (2013) who also conclude that patients and their families are very concerned with and think about existential matters and death anxiety. Existential pain in our study concerned the meaning of death and whether death would be painful, as well as a desire for death. It was also about the way the patients often stayed alive and continued suffering just for the sake of their family. It seems that existential suffering comes in many ways for these patients. In the literature there is currently no standard definition of existential pain, but generally, existential pain has been used as a metaphor for suffering (Saunders, 1988; McGrath, 2002, 2003; Musi, 2003; Strang et al., 2004). Strang et al. (2004) concluded that it is obvious that existential pain is not a uniformly defined entity, as it obviously can be understood both as existential suffering and/or pain expressed in physical terms. They also found that it is seen as a clinically important factor that may reinforce existing physical pain or may even be the primary cause of pain, in firm agreement with the current definition of pain disorder or somatization disorder (Strang et al., 2004). Gonen et al. (2012) posit that death anxiety should not be regarded as a normal consequence of having cancer; rather, that it is associated with anxiety, depressive symptoms, and physical distress, and the fact that life expectancy is short in these patients. Alternatively, dying is a transition that goes beyond anxiety according to Renz et al. (2013). During this process, patients may struggle and do not want to let go of life which may be perceived by the family that patients struggle to stay alive and continue to suffer for the sake of the family. 
It was very hard for nurses to care for patients who expressed a desire to die because the feelings of worry and anxiety were so severe that the patient could not see any other way out but death. This is a controversial topic and may contribute to why the fact that some patients desire death is not commonly debated in the literature. According to Hudson et al. (2006), reasons for a desire to die are preliminary psychological, existential and social. Desire for death could also have its origin in an anxiety towards living life with severe illness (Strang et al., 2013). Knowledge is lacking about how healthcare professionals should address patients' desire to die and the reasons for this desire. Nurses encountering end-of-life cancer patients in our study who expressed a desire to die did not perceive that patients were depressed as this is a common psychiatric reason or that the patients sensed hopelessness. Desire to die was described by Dees et al. (2011) as living with unbearable suffering specifically related to feelings of hopelessness. Suffering was not constantly unbearable in all patients except for patients having a psychiatric diagnosis. In our study there were also stories around positive situations, when patients expressed their thoughts and feelings about death, and nurses had the time and opportunity to listen without trying to change the subject and talk about other things.

In those patients experiencing lost relationships there were descriptions of the patients' loneliness, isolation, withdrawal and grief. The nurses also described all the feelings that patients expressed around not being able to take care of their children as before and the guilt that caused them. Keeping a professional distance when caring for patients who had small children of the same age as their own was a challenge for many of the nurses, and in these cases, nurses often expressed being able to identify with the patients. For some of the nurses it was described as losing a close friend when the patient died. This problem has been highlighted in earlier studies as has the importance of maintaining the balance between the output and input of energy in a caregiver's professional and personal life. The author concluded that to prevent worker burnout, hospice caregivers must develop a plan of self-care to balance their own needs with the needs of their patients (Jones, 2005). In a recent study by Udo et al. (2013) on surgical nurses' experiences of existential situations when caring for people with cancer, the authors emphasize the impact of the integration of personal self in their professional role. They concluded that whether or not nurses' personal self is integrated might have consequences for the caring process in existential situations. Their findings show how some surgical nurses integrate their personal self in their caring whereas others do not, and how some nurses are caught somewhere in-between. The results showed that inner dialogues for meaningful caring were an ongoing process described by nurses as a form of reflection, where they related to personal experiences through turning inwards during and after arduous caring situations to better understand and manage the situation. Being able to relate and identify patients' experiences with personal experiences influenced nurses, enabling them to see and understand patients from a more comprehensive point of view (Udo et al., 2013).

In the theme encountering experiences of hope, nurses balanced honesty with withholding truths, and described the patient's desire to live. Balancing honesty and having to withhold information concerned feelings of powerlessness when the nurse was forced to delay giving information to the patients. Withholding the truth was a particularly difficult ethical dilemma for the nurses; they want to respect the patient's desire to protect children, while at the same time it is important to them that the families are kept well informed so that they in turn are able to do and say what their own wishes are in relation to the circumstances. The literature is scarce concerning truth-telling in palliative care but according to Shaw
(2008), it is widely discussed in the care setting, especially in relation to hope and meaning. To tell the truth to a patient in a meaningful and supportive way, healthcare professionals must be aware of how they express truth and how patients experience and construct truth. In cancer care, information is, by tradition, filtered by the doctor with the intention to protect the patient, or it is provided gradually (Fallowfield et al., 2002; Deschepper et al., 2008). This strategy makes nurses feel uncomfortable in their relationship with the patient leading to avoidance behavior as well as feelings of powerlessness and frustration with the family and medical colleagues (Costello, 2000; Georges and Grypdonck, 2002). To our knowledge the research about family withholding the truth from patients is scarce, but Tuckett (2004) suggests that health professionals must ask patients and families what information they prefer to know.

A patient's desire to live is concerned with existential matters such as searching for meaning and focus and hanging on to life. They reflect over what they could have done differently earlier in life in a kind of retrospective thinking and learning process that they shared with nurses. This reflective process over past actions may help patients clarify how they dealt with existential crises earlier in life. Furthermore, it may support patients to focus on life in the present and to reformulate a difficult situation into something positive. Accepting that life is finite puts patients in an insecure and unstable situation. Bruce and Boston (2011) describe this position as longing for ground in a groundless world. Being aware that death is imminent may recreate an existential crisis, reminding the patients of past actions that strengthen the desire to die or the desire to live. That is, existential suffering is a process that may be triggered by such negative feelings as death anxiety, fear and bereavement and may cause these feelings to last for a longer or a shorter period of time. Existential suffering may be unbearable, as described by Dees et al. (2011), but is not endless. Telling stories repeatedly to nurses who respond with active listening and openness may support patients to strive for security and stability or a more profound grounding of their impending death, as described by Bruce and Boston (2011). Confronting life and death through deep reflections could be related to the tension when facing death described by Yalom (1980). Facing death may trigger the patients to think about their imminent death as well as cause a desire to live longer, and, in that way, they hover between these existential dimensions.

\section{Methodological considerations}

The results from this study cannot be generalized to speak for all healthcare staff experiences, nevertheless, staff other than those in these contexts may, however, be expected to have similar existential experiences. Therefore, healthcare staff in general may well gain from the insights provided in the findings. CIT as a method of collecting data exhibits both weaknesses and strengths. One of the problems in using this method was attaining vivid descriptions in writing. Some of the participants expressed uncertainty about writing down deep emotional experiences. Furthermore, many of the staff had worked for many years in a hospice or within palliative care and they could therefore be more positive towards existential narratives than the less experienced staff. The results could also have been different for the present study if the analysis had been completed for each setting separately.

In this study several steps were taken to ensure that the findings were as trustworthy as possible. The process in this study has been thoroughly described to establish coherence.

Credibility in the analysis was enhanced by continuously switching between the whole and the parts, and comparing and revising until the final themes and categories were found. Rigor 
was ensured by systematically analyzing the data, repeatedly reading, identifying, and reflecting on the critical incidents. To increase credibility, two of the authors ( $\mathrm{MB}$ and $\mathrm{IH}$ ) discussed the themes and categories including direct quotations in order to reduce bias which is recommended by Flanagan (1954). Finally, three researchers (CM, ED, SS) not previously involved in the study reviewed and commented on the themes and categories, which included citations. Some of the CITs offered rich descriptions, which could be described as narrations. Trustworthiness was considered when assessing quality during the entire research process of this study; both while planning the study, and conducting it (Patton, 2002).

\section{Conclusions}

- Healthcare professionals need to be aware of patients' feelings of abandonment in exposed situations such as patients' feelings of existential loneliness in that they feel abandoned or that they themselves had abandoned their children and other relatives.

- The situations when patients expressed a desire to die were frequently mentioned and the nurses felt uncomfortable and it was difficult to confront these occurrences. This is an area that is not often discussed and it seams, as the health care staff needs support to handle and discuss these experiences.

- Balancing honesty with withholding truths concerns the dilemmas described by the nurses about their feelings of ambiguity when they know more about the patient's situation, e.g. test results, than they are allowed to tell them.

- Reflection, education and research are needed concerning how nurses encounter patients' existential pain and preserve hope.

- This study points out the importance of listening to patients' stories, regardless of care organization, in order to help the patients to summarize their life, reflect over it and be prepared to encounter the end of their lives. The life stories provide the nurses with information for assessment purposes. Through the stories the nurses also gain access to patients' inner existential needs.

\section{Conflict of interest}

None.

\section{Acknowledgments}

The authors acknowledge all the nurses (registered nurses and enrolled) that took part in this study and shared their experiences of existential situations when caring for patients severely affected by cancer by writing critical incidences. We wish to thank Aileen Ireland for revising the use of English.

\section{References}

Adelbratt, S., Strang, P., 2000. Death anxiety in brain tumour patients and their spouses. Palliative Medicine 14, 499-507.

Aldridge, D., 2000. Spirituality, Healing and Medicine. Jessica Kingsley Publisher, London.

Beck, I., Tornquist, A., Brostrom, L., Edberg, A.K., 2011. Having to focus on doing rather than being-Nurse assistants' experience of palliative care in municipa residential care settings. International Journal of Nursing Studies 49, 455-464. http://dx.doi.org/10.1016/j.ijnurstu.2011.10.016. Epub 2011 Nov 12.

Bradbury-Jones, C., Tranter, S., 2008. Inconsistent use of the critical incident technique in nursing research. Journal of Advanced Nursing 64, 399-407.

Browall, M., Melin-Johansson, C., Strang, S., Danielson, E., Henoch, I., 2010. Health care nurses's opinions about existential issues among patients with cancer. Palliative and Supportive Care 8, 59-68.
Bruce, A., Boston, P., 2011. Relieving existential suffering through palliative sedation: discussion of an uneasy practice. Journal of Advanced Nursing 67, 2732-2740. http://dx.doi.org/10.1111/j.1365-2648.2011.05711.

Chochinov, H.M., Hack, T., Hassard, T., Kristjanson, L.J., McClement, S., Harlos, M. 2005. Understanding the will to live in patients nearing death. Psychosomatics 46, 7-10.

Chochinov, H.M., Hassard, T., McClement, S., Hack, T., Kristjanson, L.J., Harlos, M. et al., 2009. The landscape of distress in the terminally ill. Journal of Pain and Symptom Management 38, 641-649. http://dx.doi.org/10.1016/j.jpainsymman.2009.04.021. Epub 2009 Aug 26.

Clayton, J.M., Butow, P.N., Arnold, R.M., Tattersall, M.H., 2005. Discussing end-of-life issues with terminally ill cancer patients and their carers: a qualitative study. Supportive Care in Cancer 13, 589-599. Epub 2005 Jan 12.

Costello, J., 2000. Truth telling and the dying patient: a conspiracy of silence? International Journal of Palliative Nursing 6, 398-405.

de Vogel-Voogt, E., van der Heide, A., van Leeuwen, A.F., Visser, A., van der Rijt, C.C. van der Maas, P.J., 2007. Patient evaluation of end-of-life care. Palliative Medicine 21, 243-248.

Dees, M.K., Vernooij-Dassen, M.J., Dekkers, W.J., Vissers, K.C., van Weel, C., 2011. 'Unbearable suffering': a qualitative study on the perspectives of patients who request assistance in dying. Journal of Medical Ethics 37, 727-734. http:// dx.doi.org/10.1136/jme.2011.045492. Epub 2011 Sep. 24.

Deschepper, R., Bernheim, J.L., Robert Vander Stichele, R.V., Van den Block, L. Michiels, E., Van Der Kelen, G., et al., 2008. Truth-telling at the end of life: a pilot study on the perspective of patients and professional caregivers. Patient Education and Counseling 71, 52-56.

Fallowfield, L.J., Jenkins, V.A., Beveridge, H.A., 2002. Truth may hurt but deceit hurts more: communication in palliative care. Palliative Medicine 16, 297-303.

Flanagan, J.C., 1954. The critical incident technique. Psychological Bulletin 51, $327-358$

Georges, J.J., Grypdonck, M., 2002. Moral problems experienced by nurses when caring for terminally ill people: a literature review. Nursing Ethics 9, 156-177.

Gonen, G., Kaymak, S.U., Cankurtaran, E.S., Karslioglu, E.H., Ozalp, E., Soygur, H., 2012 The factors contributing to death anxiety in cancer patients. Journal of Psychosocial Oncology 30, 347-358. http://dx.doi.org/10.1080/07347332.2012.664260.

Henoch, I., Danielson, E., Strang, S., Browall, M., Melin-Johansson, C., 2013. Training intervention for nurses in the provision of existential support to patients with cancer: a randomized, controlled study. Journal of Pain and Symptom Management 46 (6), 785-794. http://dx.doi.org/10.1016 j.jpainsymman.2013.01.013.

Hudson, P.L., Kristjanson, L.J., Ashby, M., Kelly, B., Schofield, P., Hudson, R., et al, 2006. Desire for hastened death in patients with advanced disease and the evidence base of clinical guidelines: a systematic review. Palliative Medicine 20, 693-701.

Iranmanesh, S., Axelsson, K., Sävenstedt, S., Häggström, T., 2009. A caring relationship with people who have cancer. Journal of Advanced Nursing 65 1300-1308. http://dx.doi.org/10.1111/j.1365-2648.2009.04992.x. Epub 2009 Apr 3.

Johnston, B., Smith, L.N., 2006. Nurses' and patients' perceptions of expert palliative nursing care. Journal of Advanced Nursing 54, 700-709.

Jones, S.H., 2005. A self-care plan for hospice workers. The American Journal of Hospice \& Palliative Care 22, 125-128.

Krippendorff, K., 2004. Content Analysis. An Introduction to its Methodology. Sage London.

Leung, D., Esplen, M.J., 2010. Alleviating existential distress of cancer patients: can relational ethics guide clinicians? European Journal of Cancer Care 19, 30-38.

McGrath, P., 2002. Creating a language for 'spiritual pain' through research: a beginning. Supportive Care in Cancer 10, 637-646.

McGrath, P., 2003. Spiritual pain: a comparison of findings from survivors and hospice patients. American Journal of Hospice and Palliative Care 20, 23-33.

McSherry, W., Cash, K., 2004. The language of spirituality: an emerging taxonomy. International Journal of Nursing Studies 41, 151-161.

Missel, M., Birkelund, R., 2011. Living with incurable oesophageal cancer. A phenomenological hermeneutical interpretation of patient stories. European Journal of Oncology Nursing 15, 296-301. http://dx.doi.org/10.1016 j.ejon.2010.10.006. Epub 2010 Dec 10.

Mok, E., Chiu, P.C., 2004. Nurse-patient relationships in palliative care. Journal of Advanced Nursing 48, 475-483.

Musi, M., 2003. Creating a language for "spiritual pain:" why not to speak and think in terms of "spiritual suffering"? Supportive Care in Cancer 11, 378-379.

Österlind, J., Hansebo, G., Andersson, J., Ternestedt, B.-M., Hellström, I., 2011. A discourse of silence: professional carers reasoning about death and dying in nursing homes. Ageing \& Society 31, 529-544.

Patton, M.Q., 2002. Qualitative Research and Evaluation Methods. Sage, Thousand Oaks, CA.

Pelusi, J., Krebs, L.U., 2005. Understanding cancer-understanding the stories of life and living. Journal of Cancer Education 20, 12-16.

Rasmussen, B.H., Tishelman, C., Lindqvist, O., 2010. Experiences of living with a deteriorating body in late palliative phases of cancer. Current Opinion on Supportive and Palliative Care 4, 153-157. http://dx.doi.org/10.1097/ SPC.0b013e32833b4f37.

Renz, M., Mao, M.S., Bueche, D., Cerny, T., Strasser, F., 2013. Dying is a transition. The American Journal of Hospice Palliative Care 30, 283-290. http://dx.doi.org 10.1177/1049909112451868. Epub 2012 Jul 12.

Saunders, C., 1988. Spiritual pain. Journal of Palliative Care 4, 9-32. 
Shaw, S., 2008. Exploring the concepts behind truth-telling in palliative care. International Journal of Palliative Nursing 14, 356-359.

Strang, S., 2006. chapter. In: Bruera, Higgins (Eds.), Spiritual Care. Textbook of Palliative Medicine, vol. 109. Hodder Arnold.

Strang, S., Strang, P., 2001. Spiritual thoughts, coping and 'sense of coherence' in brain tumour patients and their spouses. Palliative Medicine 15, 127-134.

Strang, S., Strang, P., Ternestedt, B.M., 2002. Spiritual needs as defined by Swedish nursing nurses. Journal of Clinical Nursing 11, 48-57.

Strang, P., Strang, S., Hultborn, R., Arnér, S., 2004. Existential pain-an entity, a provocation, or a challenge? Pain and Symptom Management 27, 241-250.

Strang, S., Ekberg-Jansson, A., Henoch, I., 2013. Experience of life and death anxiety among patients with severe COPD-a qualitative, in-depth interview study. Palliative \& Supportive Care, 1-8 [Epub ahead of print].
Taylor, E.J., 1997. The story behind the story: the use of storytelling in spiritual caregiving. Seminars in Oncology Nursing 13, 252-254.

Tuckett, A.G., 2004. Truth-Telling in clinical practice and the arguments for and against: a review of the literature. Nursing Ethics 11, 500-513.

Udo, C., Danielson, E., Melin-Johansson, C., 2013. Existential issues among nurses in surgical care-a hermeneutical study of critical incidents. Journal of Advanced Nursing 69, 569-577. http://dx.doi.org/10.1111/j.1365-2648.2012.06032.x.

Yalom, I.D., 1980. Existential Psychotherapy. Simon \& Shuster, New York.

Yardley, S.J. Walshe, C.E., Parr, A., 2009. Improving training in spiritual care: a qualitative study exploring patient perceptions of professional educational requirements. Palliative Medicine 23, 601-607. 